AperTO - Archivio Istituzionale Open Access dell'Università di Torino

\title{
Bleeding prevalence and transfusion requirement in patients with thrombocytopenia in the emergency department
}

\section{This is the author's manuscript}

Original Citation:

Availability:

This version is available http://hdl.handle.net/2318/1551174

since 2018-05-20T12:55:50Z

Published version:

DOI:10.1515/cclm-2014-0224

Terms of use:

Open Access

Anyone can freely access the full text of works made available as "Open Access". Works made available under a Creative Commons license can be used according to the terms and conditions of said license. Use of all other works requires consent of the right holder (author or publisher) if not exempted from copyright protection by the applicable law. 
Fabrizio Turvani, Luca Pigozzi, Letizia Barutta, Emanuele Pivetta, Elisa Pizzolato, Fulvio Morello, Stefania Battista, Corrado Moiraghi, Giuseppe Montrucchio and Enrico Lupia*, on behalf of GREAT Network

\section{Bleeding prevalence and transfusion requirement in patients with thrombocytopenia in the emergency department}

\begin{abstract}
Background: Thrombocytopenia is the most common coagulation disorder in critically ill patients. No studies have investigated the epidemiology and clinical impact of this condition in emergency department (ED) patients. We aimed to investigate epidemiological features, incidence of bleeding, and diagnostic and therapeutic requirements of patients with thrombocytopenia admitted to the ED.

Methods: We performed a retrospective observational study enrolling all patients admitted to the medical-surgical ED of the "Città della Salute e della Scienza di Torino" Hospital with a platelet count $<150 \times 10^{9} \mathrm{PLTs} / \mathrm{L}$, during four non-consecutive months. There were no exclusion criteria.

Results: The study included 1218 patients. The percentage of patients with severe $\left(<50 \times 10^{9} \mathrm{PLTs} / \mathrm{L}\right)$ or very severe $\left(<20 \times 10^{9}\right.$ PLTs/L) thrombocytopenia was about $12 \%$. Thrombocytopenia associated with liver cirrhosis was the most represented etiology. On the contrary, the most frequent cause in patients with newly recognized low platelet count was disseminated intravascular coagulation/sepsis. The incidence of bleeding and hypovolemia, as well as the need of transfusional support and mechanical, surgical or endoscopic hemostasis progressively increased with the severity of thrombocytopenia.
\end{abstract}

\footnotetext{
*Corresponding author: Dr. Enrico Lupia, MD, Department of Medical Sciences, University of Turin, Via Genova 3, 10126, Torino, Italy, Phone: +39 011 6705395, Fax: +39 0116705367 ,

E-mail: enrico.lupia@unito.it; and Emergency Medicine Unit, “Città della Salute e della Scienza di Torino" Hospital, Turin, Italy Fabrizio Turvani, Luca Pigozzi, Emanuele Pivetta and Elisa Pizzolato: Department of Medical Sciences, University of Turin, Turin, Italy; and Emergency Medicine Unit, "Città della Salute e della Scienza di Torino" Hospital, Turin, Italy Letizia Barutta and Giuseppe Montrucchio: Department of Medical Sciences, University of Turin, Turin, Italy Fulvio Morello, Stefania Battista and Corrado Moiraghi: Emergency Medicine Unit, "Città della Salute e della Scienza di Torino" Hospital, Turin, Italy
}

Conclusions: Our results suggest that the detection of a platelet count lower than $50 \times 10^{9}$ PLTs/L may help to identify patients with higher bleeding risk in the ED setting. Additional studies are required to evaluate whether, in this setting, thrombocytopenia may represent an independent risk factor for bleeding episodes and increased mortality.

Keywords: bleeding risk; emergency department; platelets; thrombocytopenia; transfusions.

DOI 10.1515/cclm-2014-0224

Received February 28, 2014; accepted April 16, 2014

\section{Introduction}

Thrombocytopenia is the most common coagulation disorder in critically ill patients [1]. Low platelet (PLT) count, even though not associated with bleeding, influences patient management and treatment decisions [2]. Thrombocytopenia, indeed, often prompts physicians to reassess timing of invasive interventions, anticoagulation intensity, and may also leads to prophylactic PLT transfusion for correction of PLT count values [2]. Moreover, thrombocytopenia, usually defined as a PLT count lower than $150 \times 10^{9} \mathrm{PLTs} / \mathrm{L}[3,4]$, has been proven an independent risk factor for both longer intensive care unit (ICU) length of stay [3, 5-7] and higher mortality in critically ill patients [3, 5-8]. Finally, although illness severity scoring systems inconsistently consider PLT count, ICU patients with thrombocytopenia have illness severity scores, such as MODS or APACHE-II higher than those without thrombocytopenia $[6,7]$.

Whereas thrombocytopenia is of common occurrence in patients entering the emergency department (ED), no studies specifically investigated the epidemiology and clinical impact of this condition in ED patients. Only 
a previous observational study, conducted on a small patient cohort of 115 ED patients, reported an incidence value of about $10 \%$ [9].

The aim of this study was to investigate epidemiological features, incidence of bleeding, and diagnostic and therapeutic requirements of patients with thrombocytopenia admitted to the ED.

\section{Materials and methods}

We performed a retrospective observational study enrolling all patients admitted to the medical-surgical ED of the "Città della Salute e della Scienza di Torino" Hospital with a PLT count $<150 \times 10^{9}$ PLTs/L, during four non-consecutive months (January, April, July, October, 2012). There were no exclusion criteria.

We classified the severity of thrombocytopenia as mild, moderate, severe, or very severe on the basis of PLT count $<150 \times 10^{9}$ PLTs/L, $<100 \times 10^{9}$ PLTs/L, $<50 \times 10^{9}$ PLTs/L, or $<20 \times 10^{9}$ PLTs/L, respectively, according to a previously published study [7].

Data we collected included demographic data, co-morbidities, drugs used in the last 2-week period before admission, HIV infection, most recent PLT count before admission (within 6 months), and ED admission category. In addition, we recorded the occurrence of bleeding, packed red blood cell (PRBC) and PLT transfusion requirement, and the need to perform surgical/endoscopic mechanical hemostasis, or hematologic consultation.

We considered major bleeding episodes those that caused drop in hemoglobin values $>2 \mathrm{~g} / \mathrm{dL}$, those requiring mechanical hemostasis or PRBC transfusions within $24 \mathrm{~h}$, and all intracranial hemorrhages.

The etiology of thrombocytopenia was derived by medical records.

The study was conducted according to the Helsinki Declaration, and approved by our Institutional Ethical Committee.

\section{Results}

During the study period, we enrolled 1218 patients admitted to our ED with a PLT count $<150 \times 10^{9}$ PLTs/L. Table 1 gives demographic and clinical data of patients.

Most patients were of older age (median \pm SD $69.00 \pm 17.7$ years; range 14-99 years), and required ED evaluation related to a non-surgical admission category $(75.9 \%)$. In only $2.8 \%$ of all patients, the major clinical problem leading to ED evaluation was directly associated with thrombocytopenia, in particular, the occurrence of petechiae and minor or major bleeding episodes in patient with no other hemorrhagic diathesis. In addition, patients were generally affected by more than two associated pathologies.

Most of the patients $(>85 \%)$ had mild or moderate thrombocytopenia, whereas the percentage of patients
Table 1 Demographic and clinical characteristic of patients.

\begin{tabular}{lr}
\hline Sex, M/F (\% males) & $830 / 388(67.4 \%)$ \\
Age, median \pm SD (range) & $69.00 \pm 17.7(14-99)$ \\
Medical admission, $n(\%)$ & $925(75.9 \%)$ \\
Admission category, $\%$ & \\
Strictly related to thrombocytopenia & $34(2.8 \%)$ \\
Pneumologic & $109(8.9 \%)$ \\
Cardiovascular & $170(14.1 \%)$ \\
Gastrointestinal & $196(16.1 \%)$ \\
Hepatic & $140(11.4 \%)$ \\
Neurologic & $93(7.6 \%)$ \\
Sepsis & $102(8.4 \%)$ \\
Orthopedic & $70(5.7 \%)$ \\
Ematologic & $39(3.2 \%)$ \\
Nephro-urologic & $108(8.9 \%)$ \\
Other & $157(12.8 \%)$ \\
Comorbidities, mean \pm SD & $2.22 \pm 1.28$ \\
Platelet count at admission & \\
$101-150 \times 10^{9}$ PLTs/L, $n(\%)$ & $794(65.3 \%)$ \\
$51-100 \times 10^{9}$ PLTs/L, $n(\%)$ & $277(22.7 \%)$ \\
$21-50 \times 10^{9}$ PLTs/L, $n(\%)$ & $99(8 \%)$ \\
$<20 \times 10^{9}$ PLTs/L, $n(\%)$ & $48(4 \%)$ \\
\hline
\end{tabular}

with severe or very severe thrombocytopenia was slightly above $12 \%$. Table 2 lists the causes of thrombocytopenia found in the study cohort.

Thrombocytopenia associated with liver cirrhosis was the most represented cause of thrombocytopenia, accounting for about $1 / 5$ of all patients. On the contrary, in patients with newly recognized low PLT count, the most frequent cause was represented by thrombocytopenia associated to disseminated intravascular coagulation (DIC)/sepsis.

In the half of cases, the cause of thrombocytopenia was either unspecified or not investigated during the hospital stay; however, the great majority of these patients

Table 2 Etiology of thrombocytopenia.

\begin{tabular}{lr}
\hline Liver cirrhosis, $\mathrm{n}(\%)$ & $248(20.4 \%)$ \\
$\begin{array}{l}\text { Blood cancers (leukemia, lymphoma, multiple } \\
\text { myeloma), } \mathrm{n}(\%)\end{array}$ & $126(10.3 \%)$ \\
$\begin{array}{l}\text { Chemotherapy-induced thrombocytopenia, } \mathrm{n}(\%) \\
\text { Immune thrombocytopenia, } \mathrm{n}(\%)\end{array}$ & $68(5.6 \%)$ \\
Disseminated intravascular coagulation (DIC)/ & $44(3.6 \%)$ \\
$\quad$ Sepsis, n (\%) & $41(3.3 \%)$ \\
Drug-associated thrombocytopenia, n (\%) & $24(1.9 \%)$ \\
Post-viral illness thrombocytopenia, n (\%) & $24(1.9 \%)$ \\
Solid cancers, n (\%) & $20(1.7 \%)$ \\
Autoimmune diseases, n (\%) & $9(0.7 \%)$ \\
Thrombotic thrombocytopenic purpura, n (\%) & $2(0.2 \%)$ \\
Pseudothrombocytopenia, n (\%) & $2(0.2 \%)$ \\
Unspecified, n (\%) & $610(50.1 \%)$ \\
\hline
\end{tabular}


Table 3 Incidence of bleeding according to thrombocytopenia severity.

\begin{tabular}{|c|c|c|c|c|}
\hline & $\begin{array}{r}\text { Mild } \\
\left(101-150 \times 10^{9}\right)\end{array}$ & $\begin{array}{r}\text { Moderate } \\
\left(51-100 \times 10^{9}\right)\end{array}$ & $\begin{array}{r}\text { Severe } \\
\left(21-50 \times 10^{9}\right)\end{array}$ & $\begin{array}{r}\text { Very severe } \\
\left(<20 \times 10^{9}\right)\end{array}$ \\
\hline Pethechiae, \% (n) & $3.4 \%(37)$ & $12.6 \%(35)$ & $33.3 \%(33)$ & $54.2 \%(26)$ \\
\hline Minor bleedings, \% (n) & $6.3 \%(50)$ & $7.6 \%(21)$ & $8.1 \%(8)$ & $41.7 \%(20)$ \\
\hline Major bleedings, \% (n) & $3.0 \%(24)$ & $4.3 \%(12)$ & $9.1 \%(9)$ & $16.7 \%(8)$ \\
\hline Hypovolemia, \% (n) & $1.8 \%(14)$ & $4.3 \%(12)$ & $7.1 \%(7)$ & $8.3 \%(4)$ \\
\hline
\end{tabular}

(89.8\%) presented with mild or moderate thrombocytopenia, and none with severe or very severe thrombocytopenia. Only few patients were submitted to bone marrow aspiration/biopsy during the hospital stay, none of them in the ED.

Table 3 gives the incidence of bleeding according to the severity of thrombocytopenia. A total of 137 patients (11.2\%) experienced a bleeding episode, of whom 53 were categorized as major bleedings. As expected, the incidence of bleeding and of hypovolemia was higher in patients with lower PLT count.

Table 4 shows the therapeutic/diagnostic interventions performed during the ED stay according to thrombocytopenia severity. The need of PRBC and PLT transfusions, mechanical hemostasis interventions, and hematologic consultations increased with the severity of thrombocytopenia.

\section{Discussion}

This is the first study aimed to investigate the epidemiological features, the incidence of bleeding, and the diagnostic and therapeutic requirements of patients with thrombocytopenia admitted to the ED. Previous studies investigated the incidence and prognostic impact of thrombocytopenia in ICU $[3,6-8,10]$ or onco-hematologic patients [11-14]. However, these patient populations are very different from patients admitted to the ED, making it very difficult to extrapolate the results coming from these studies to the ED setting.
The most innovative result of our study is the demonstration that patients with severe or very severe thrombocytopenia $\left(<50 \times 10^{9} \mathrm{PLTs} / \mathrm{L}\right)$, although accounting for only about $12 \%$ of all thrombocytopenic ED patients, experienced major bleeding episodes in a significantly larger percentage (17/137 patients, $11.5 \%)$ compared to patients with less severe thrombocytopenia (36/1071 patients, 3.4\%). In addition, the management of ED patients with lower PLT counts required the employment of more diagnostic resources and therapeutic interventions, as indicated by the higher need of PRBC (22.4\%) and PLT (25.2\%) transfusions, mechanical hemostasis interventions (10.9\%), and hematologic consultations (38.1\%).

Demographic characteristics of our study cohort were heterogeneous. The advanced age, the variety of admission categories, and the high number of comorbidities make our study population representative of the complexity of patients entering a big inner city ED.

The etiology of thrombocytopenia in our study cohort was also very heterogeneous. Most of our knowledge in this field is based on studies performed in oncohematological patients in stable conditions, in whom central thrombocytopenia, due to reduced bone marrow thrombopoiesis, has been shown the main mechanism responsible for low PLT count [11-14]. On the contrary, in critically ill patients admitted in the ICU, thrombocytopenia is more often caused by increased PLT consumption, mainly consequent to the development of sepsis and/or DIC [10, 15]. Interestingly, in critically ill patients, the relationship between thrombocytopenia and bleeding risk is less stringent than in onco-hematologic patients $[6,7]$,

Table 4 Therapeutic/diagnostic intervention requirement according to thrombocytopenia severity.

\begin{tabular}{|c|c|c|c|c|}
\hline & $\begin{array}{r}\text { Mild } \\
\left(101-150 \times 10^{9}\right)\end{array}$ & $\begin{array}{r}\text { Moderate } \\
\left(51-100 \times 10^{9}\right)\end{array}$ & $\begin{array}{r}\text { Severe } \\
\left(21-50 \times 10^{9}\right)\end{array}$ & $\begin{array}{r}\text { Very severe } \\
\left(<20 \times 10^{9}\right)\end{array}$ \\
\hline PRBC transfusion & $3.8 \%(30)$ & $6.5 \%(24)$ & $24.2 \%(18)$ & $31.9 \%(15)$ \\
\hline PLT transfusion & $0.4 \%(3)$ & $1.8 \%(5)$ & $8.1 \%(8)$ & $61.7 \%(29)$ \\
\hline Endoscopic hemostasis & $2.1 \%(17)$ & $3.6 \%(10)$ & $5.0 \%(5)$ & $14.9 \%(7)$ \\
\hline Surgical hemostasis & $0.6 \%(5)$ & $0 \%(0)$ & $2.0 \%(2)$ & $4.4 \%(2)$ \\
\hline Hematologic consultation & $1.4 \%(36)$ & $2.5 \%(37)$ & $16.1 \%(25)$ & $31.2 \%(31)$ \\
\hline
\end{tabular}


probably related to the preserved production of functional PLTs $[10,16]$. In our study, the most represented etiology was thrombocytopenia associated with liver cirrhosis; however, analogously to what is observed in ICU patients $[10,15]$, the first cause of low PLT count in patients with newly recognized thrombocytopenia resulted DIC/sepsis.

In our study, the cause of thrombocytopenia was either unspecified or not investigated during the hospital stay in about half of the patients. Since most of them had mild or moderate thrombocytopenia, and none had severe or very severe thrombocytopenia, therefore very low rate of bleeding complications, the attitude of ED physicians not to spend diagnostic and therapeutic resources on these patients seems to be appropriate.

Several limits have to be taken into account in interpreting our results. The retrospective design limits the information that can be obtained concerning possible etiologies for the thrombocytopenia, which remained unspecified in about $50 \%$ of the patients enrolled in our study. Moreover, the number of patients affected by severe or very severe thrombocytopenia was relatively low. Finally, we did not evaluate, in the present study, whether thrombocytopenia and the need for blood component transfusion correlate with mortality in the ED setting. Additional studies are required to evaluate whether thrombocytopenia may represent an independent risk factor for bleeding episodes and increased mortality.

In conclusion, our results suggest that the detection of a PLT count lower than $50 \times 10^{9}$ PLTs/L may contribute to identify patients with higher bleeding risk in the ED setting.

Acknowledgments: This work was supported by Ministero dell'Università e della Ricerca Scientifica e Tecnologica (MURST) ex-60\%, and Progetto di Ricerca Sanitaria Finalizzata - Regione Piemonte to GM and EL.

\section{Conflict of interest statement}

Authors' conflict of interest disclosure: The authors stated that there are no conflicts of interest regarding the publication of this article. Research support played no role in the study design; in the collection, analysis, and interpretation of data; in the writing of the report; or in the decision to submit the report for publication.

Research funding: None declared.

Employment or leadership: None declared.

Honorarium: None declared.

\section{References}

1. Chakraverty R, Davidson S, Peggs K, Stross P, Garrard C, Littlewood TJ. The incidence and cause of coagulopathies in an intensive care population. Br J Haematol 1996;93:460-3.

2. Greinacher A, Selleng K. Thrombocytopenia in the intensive care unit patient. Hematology Am Soc Hematol Educ Program 2010; 2010:135-43.

3. Crowther MA, Cook DJ, Meade MO, Griffith LE, Guyatt GH, Arnold DM, et al. Thrombocytopenia in medical-surgical critically ill patients: prevalence, incidence, and risk factors. J Crit Care 2005;20:348-53.

4. Hui P, Cook DJ, Lim W, Fraser GA, Arnold DM. The frequency and clinical significance of thrombocytopenia complicating critical illness: a systematic review. Chest 2011;139:271-8.

5. Baughman RP, Lower EE, Flessa HC, Tollerud DJ. Thrombocytopenia in the intensive care unit. Chest 1993;104:1243-7.

6. Vanderschueren S, De Weerdt A, Malbrain M, Vankersschaever $D$, Frans E, Wilmer A, et al. Thrombocytopenia and prognosis in intensive care. Crit Care Med 2000;28:1871-6.

7. Strauss R, Wehler M, Mehler K, Kreutzer D, Koebnick C, Hahn EG. Thrombocytopenia in patients in the medical intensive care unit: bleeding prevalence, transfusion requirements, and outcome. Crit Care Med 2002;30:1765-71.

8. Williamson DR, Lesur O, Tétrault J-P, Nault V, Pilon D. Thrombocytopenia in the critically ill: prevalence, incidence, risk factors, and clinical outcomes. Can J Anaesth 2013;60:641-51.

9. Howell MD, Powers RD. Utility of thrombocytopenia as a marker for heparin allergy in adult ED patients. Am J Emerg Med 2006;24:268-70.

10. Thiolliere F, Serre-Sapin AF, Reignier J, Benedit M, Constantin JM, Lebert C, et al. Epidemiology and outcome of thrombocytopenic patients in the intensive care unit: results of a prospective multicenter study. Intens Care Med 2013;39:1460-8.

11. Rebulla P, Finazzi G, Marangoni F, Avvisati G, Gugliotta L, Tognoni G, et al. The threshold for prophylactic platelet transfusions in adults with acute myeloid leukemia. Gruppo Italiano Malattie Ematologiche Maligne dell'Adulto. N Engl J Med 1997;337:1870-5.

12. Slichter SJ, Kaufman RM, Assmann SF, McCullough J, Triulzi DJ, Strauss RG, et al. Dose of prophylactic platelet transfusions and prevention of hemorrhage. N Engl J Med 2010;362:600-13.

13. Wandt H, Schaefer-Eckart K, Wendelin K, Pilz B, Wilhelm M, Thalheimer $M$, et al. Therapeutic platelet transfusion versus routine prophylactic transfusion in patients with haematological malignancies: an open-label, multicentre, randomised study. Lancet 2012;380:1309-16.

14. Stanworth SJ, Estcourt LJ, Powter G, Kahan BC, Dyer C, Choo L, et al. A no-prophylaxis platelet-transfusion strategy for hematologic cancers. N Engl J Med 2013;368:1771-80.

15. Thiele T, Selleng K, Selleng S, Greinacher A, Bakchoul T. Thrombocytopenia in the intensive care unit - diagnostic approach and management. Semin Hematol 2013;50:239-50.

16. Pène F, Benoit DD. Thrombocytopenia in the critically ill: considering pathophysiology rather than looking for a magic threshold. Intens Care Med 2013;39:1656-9. 